\title{
Anaemia among pregnant women in northern Tanzania: prevalence, risk factors and effect on perinatal outcomes
}

\author{
SIA E. MSUYA ${ }^{1,2^{*}}$, TAMARA H. HUSSEIN ${ }^{2,3}$, JACQUELINE URIYO $^{1,2,4}$, NOEL E. SAM ${ }^{1}$ and BABILL \\ STRAY-PEDERSEN ${ }^{4}$ \\ ${ }^{1}$ Kilimanjaro Christian Medical Centre, Po Box 3010, Moshi, Tanzania \\ ${ }^{2}$ Better Health for African Mothers and Children Project, Moshi, Tanzania \\ ${ }^{3}$ School of Public Health, Moi University, Eldoret, Kenya \\ ${ }^{4}$ Rikshospitalet University Hospital, University of Oslo, N-0027, Oslo, Norway
}

\begin{abstract}
Anaemia during pregnancy is associated with negative maternal and neonatal outcomes. However, there is limited data regarding prevalence and effects of anaemia during pregnancy in northern Tanzania. The objective of this study was to determine the prevalence and possible risk factors for anaemia and its effect on perinatal outcomes among pregnant women attending antenatal care in Moshi Municipality in northern Tanzania. A cohort of pregnant women aged 14-43 years and in their $3^{\text {rd }}$ trimester, was recruited from two primary health care clinics between June 2002 and March 2004. Interviews, anthropometric measurements and haematological examinations were conducted on 2654 consenting women. Perinatal outcomes were recorded during delivery and at 1 week after delivery. Of the 2654 participants, $47.4 \%$ had anaemia (haemoglobin $[\mathrm{Hb}]<11 \mathrm{~g} / \mathrm{dl}), 35.3 \%$ had mild anaemia $(\mathrm{Hb}=9$ $10.9 \mathrm{~g} / \mathrm{dl}), 9.9 \%$ had moderate anaemia $(\mathrm{Hb}=7-8.9 \mathrm{~g} / \mathrm{dl})$, and $2.1 \%$ had severe anaemia $(\mathrm{Hb}<7 \mathrm{~g} / \mathrm{dl})$. Anaemia was significantly more prevalent in HIV-positive (56.4\%) than in HIV-negative women (46.7\%), $(P=0.01)$. In logistic regression anaemia was independently associated with maternal HIV $(\mathrm{OR}=1.5)$, malaria $(\mathrm{OR}=5.2)$, clinic of recruitment $(\mathrm{OR}=1.5)$ and low income $(\mathrm{OR}=1.9)$. Pregnant women with anaemia were more likely to have low birth weight (LBW) infants. Compared with non-anaemic women, the risk of LBW was 1.6 times and 4.8 times higher for children born to women with moderate and severe anaemia, respectively. In conclusion, anaemia in pregnancy is a severe public health problem in northern Tanzania. Control of maternal anaemia may be one important strategy to prevent LBW in this setting. Measures to prevent malaria and to control anaemia among all pregnant women irrespective of HIV status, should be strengthened. Outside of the health sector broader approaches for anaemia prevention targeting women of lower income, are required.
\end{abstract}

Key words: anaemia, pregnancy, risk factors, low birth weight, Tanzania

\section{Introduction}

Anaemia in pregnancy, (haemoglobin level $<11 \mathrm{~g} / \mathrm{dl}$ ) as defined by World Health Organization is a major public health problem, especially in developing countries (de Benoist et al., 2008). Recent statistics indicate that anaemia affects $41.8 \%$ of pregnant women globally, with the highest prevalence in Africa (WHO, 2006). Fifty seven percent of pregnant women in Africa are anaemic, which corresponds to 17 million affected women, with severe consequence on health, social, and economic development (Levin, 1986; Allen, 2000; de Benoist et al., 2008). Studies in Africa have shown a high prevalence of anaemia in pregnancy ranging from $41-83 \%$ in different settings (Meda et al., 1999; Antelman et al., 2000; TDHS, 2005; Uneke et al., 2007; Haggaz et al.,

* Correspondence: Dr. Sia E. Msuya; E-mail: siamsuya@hotmail.com 
2010; Kidanto et al., 2009;). There is however significant variation in prevalence of anaemia, both within and between countries, necessitating a need for local data to help inform preventive programmes.

Anaemia in pregnancy is associated with negative consequence for both the woman and neonate. Foetal anaemia, low birth weight (LBW), preterm birth, low APGAR score, intrauterine growth restriction, and perinatal mortality have been associated with anaemia (Scholl \& Hediger 1994; Msolla \& Kinabo, 1997; Allen, 2000; Lone et al., 2004; Adam et al., 2007; Haggaz et al., 2010; Kidanto et al., 2009). In the women themselves it may cause low physical activity and increased risk of maternal morbidity and mortality, especially in those with severe anaemia (Scholl \& Hediger, 1994; Allen, 2000; de Benoist et al., 2008).

The cause of anaemia in pregnancy is multi-factorial. Low caloric intake leading to deficiencies in iron, folate, vitamin B12 and vitamin A, as well as intestinal parasitic infections, malaria, haemoglobinopathies and HIV have all been shown to be the main causes of anaemia among pregnant African women (Msolla \& Kinabo, 1997; Verhoeff et al., 1999; Allen, 2000; Antelman et al., 2000; Uneke et al., 2007). Few studies have however assessed anaemia among pregnant women in Tanzania, especially in the third trimester when anaemia is most likely to affect the risk of maternal and perinatal outcomes (Antelman et al., 2000; Kidanto et al., 2009). It was the objective of this study to determine the prevalence of anaemia, its risk factors and its effect on perinatal outcomes among pregnant women in their $3^{\text {rd }}$ trimester, attending routine antenatal care in Moshi Municipality, northern Tanzania.

\section{Materials and Methods}

\section{Study site and population}

The study was conducted among pregnant women attending routine antenatal care at two of the largest primary health care clinics (PHC) namely, Majengo and Pasua in Moshi Municipality in March 2002 to June 2004. The Municipality is the capital of Kilimanjaro Region of northern Tanzania with a population of $\sim 230,000$ people (URT, 2002). During the study period, the Municipality had 15 wards, and six government primary health care clinics. The two centres, Majengo and Pasua, were receiving pregnant women from 10 out of 15 wards, serving a catchment population of approximately 150,000 people. Also, during the study period measurement of haemoglobin was routinely available only at the regional and referral hospitals and not at the six government primary health care facilities offering antenatal care. Reproductive health care clinics are well attended in the district, with more than $97 \%$ attending for antenatal care, and $>89 \%$ for immunization of children (TDHS, 2005).

Eligibility criteria and recruitment procedures have been described elsewhere (Msuya et al., 2006). Briefly, pregnant women attending the two clinics for routine antenatal care, who were in their third trimester and residing in Moshi urban district were eligible to participate. Women were excluded if they intended to move out of the Municipality within a year after delivery. A total of 2654 pregnant women were recruited and these women were followed in pregnancy, during delivery, at one week, one month and at every $3^{\text {rd }}$ month until 18 months post delivery. This paper is based on the analysis of data collected from pregnancy, through delivery, to seven days post delivery. 
Each participating woman was interviewed to seek information on socio-demographic variables such as education, age, parity, income and household possessions. Obstetric history and medical history including history of malaria prophylaxis and iron supplementation were also collected. After the interview, a general examination was performed where weight and height were measured and body mass index (BMI) calculated as weight in kilograms divided by the square of height in metres. Gynaecological examination was performed and blood was taken for haemoglobin estimation, and to check for malaria and diagnosis of HIV and other STIs (Msuya et al., 2006).

The women were asked to return for their results after one week. Women found to have mild or moderate anaemia $(\mathrm{Hb} 7-10.9 \mathrm{~g} / \mathrm{dl})$ at this visit were given dietary advice plus iron and folic acid supplements. Those with severe anaemia $(\mathrm{Hb}<7 \mathrm{~g} / \mathrm{dl})$, in addition to diet advice and supplements, were advised to deliver at the regional hospital. HIV positive women and their infants were given a single dose of Nevirapine (sdNVP) for prevention of mother-to-child transmission (PMTCT) of HIV. During delivery, information on gestation age at delivery, type of delivery, infant's weight, height, head circumference, APGAR scores and perinatal outcome (live birth or stillbirth) were recorded. Delivery information was available from $85 \%(\mathrm{~N}=2256)$ of the enrolled women.

\section{Laboratory methods}

Haemoglobin was measured on site, using a drop of whole blood collected in microcuvette, with the HemoCue haemoglobimeter machine (HemoCue AB, Angelholm, Sweden). Thick blood films were prepared, stained with Giemsa to check for number of asexual Plasmodium falciparum parasites per 200 white blood cells for diagnosing malaria. HIV was diagnosed by a positive result on both the Determine HIV 1/2 (Abbott Laboratories, IL, USA) and Capillus HIV 1/2 (Trinity Biotech, Ireland).

\section{Definition of terms}

Maternal anaemia was defined when haemoglobin was $<11 \mathrm{~g} / \mathrm{dl}$. Anaemia was classified as mild $(\mathrm{Hb}=9-10.9 \mathrm{~g} / \mathrm{dl})$, moderate $(\mathrm{Hb}=7-8.9 \mathrm{~g} / \mathrm{dl})$ and severe anaemia $(\mathrm{Hb}<7 \mathrm{~g} / \mathrm{dl})$, respectively (de Benoist et al., 2008). Gestational age in weeks was calculated from the first day of the last menstrual period. Preterm delivery was defined as labour before 37 completed weeks of gestation. Low birth weight was defined as $<2500$ grams. Stillbirth was defined as delivery of a dead infant after 28 weeks of gestation. Perinatal death was defined as the number of stillbirths plus the deaths of live born infants which occurred $\leq 7$ days after birth.

\section{Ethical consideration}

Ethical clearance was obtained from the Tanzanian Ministry of Health and The Regional Committee for Medical Research Ethics (Regional Komite for Medisinsk Forskninetikk Region III). A written informed consent was sought from each participant before enrolment.

\section{Statistical analysis}

The data entry, cleaning and analysis was conducted using SPSS statistical software, version 15.0 (SPSS, Chicago, IL, USA). Descriptive statistics were used to summarize the data. 
Comparison between categorical variables was made using the $\chi^{2}$ test, and for quantitative variables using the independent $t$-test or one-way ANOVA. A p-value of less than 0.05 was considered statistically significant. Multiple logistic regressions were conducted to get independent predictors of anaemia, and variables were entered in the model if they had $p$ value of $\leq 0.05$ in the univariate analysis.

\section{Results}

\section{Characteristics of the participants}

The age of the 2654 participating women ranged from 14-43 years (mean 24.6+5.4 years), parity from 0-9 (median 1) and gestation age from 28-40 weeks (median 30 weeks). Thirty six percent (968) of the women were primiparous. The majority $(91 \% ; \mathrm{N}=2414)$ of the participants were married or cohabiting and had only primary education $(86 \% ; \mathrm{N}=2275)$. Very few women were formally employed 5\% (136). Most were either housewives 31\% (818) or involved in small scale business 46\% (1224). Average monthly income was low, only 6\% (166) had an income of $\geq$ US\$30/month. Eighty two percent (2168) of the women reported taking iron tablets at least for one month during pregnancy and 58\% (1547) reported receiving 2 doses of sulfadoxinepyrimethamine (SP) for malaria prevention.

Table 1: Association of anaemia with socio-demographic, obstetric and clinical factors among 2654 pregnant women in Moshi urban, Tanzania

\begin{tabular}{|c|c|c|c|c|c|c|}
\hline \multirow[b]{2}{*}{ Variable } & \multicolumn{2}{|c|}{ Anaemic women } & \multicolumn{2}{|c|}{ Crude } & \multirow[b]{2}{*}{ OR } & Adjusted $^{*}$ \\
\hline & Number & OR & $95 \%$ & CI & & $95 \%$ CI \\
\hline \multicolumn{7}{|l|}{ Clinic recruited } \\
\hline Majengo & 1438 & $610(42.4)$ & \multicolumn{3}{|l|}{1} & \multirow{2}{*}{9} \\
\hline Pasua & 647 & $(53.2)$ & $1.32-1$ & 1.801 .51 & $1.28-1.7$ & \\
\hline \multicolumn{7}{|l|}{ Education of the woman } \\
\hline Secondary or more & 271 & $125(46.1)$ & 1 & & & \\
\hline Primary & 2275 & $1074(47.2)$ & 1.04 & $0.81-$ & $1.34-$ & \\
\hline None & 108 & $58 \quad(53.4)$ & 1.35 & $0.87-$ & $2.12-$ & \\
\hline \multicolumn{7}{|l|}{ Education of the partner } \\
\hline Secondary or more & 579 & $252(43.5)$ & 1 & & & 1 \\
\hline Primary/none & 2075 & $1005(48.4)$ & 1.22 & $1.02-$ & 1.471 .09 & $0.89-1.34$ \\
\hline \multicolumn{7}{|c|}{ Income per month (US\$) } \\
\hline$\geq 30$ & 166 & $57 \quad(34.2)$ & 1 & & & 1 \\
\hline$<30$ & 1726 & $797(46.2)$ & 1.64 & $1.17-$ & 2.291 .47 & $1.03-2.10$ \\
\hline None & 762 & $403(52.9)$ & 2.15 & $1.51-$ & 3.051 .95 & $1.34-2.84$ \\
\hline \multicolumn{7}{|c|}{ House ownership $(\mathrm{N}=2413)$} \\
\hline \multicolumn{2}{|c|}{ Own/rent whole house706 } & $289(40.9)$ & \multicolumn{3}{|l|}{1} & 1 \\
\hline Rent a room & 1707 & $831(48.7)$ & 1.37 & $1.15-$ & 1.641 .27 & $1.05-1.52$ \\
\hline \multicolumn{7}{|l|}{ Malaria } \\
\hline Negative & 2614 & $995(38.0)$ & 1 & & & 1 \\
\hline Positive & 40 & $32(80.0)$ & 6.49 & $1.82-$ & 23.16 & $5.26 \quad 1.74-22.56$ \\
\hline \multicolumn{7}{|l|}{ HIV status } \\
\hline Negative & 2470 & $1153(46.7)$ & 1 & & & 1 \\
\hline Positive & 184 & $104(56.5)$ & 1.49 & 1.09 & 2.011 .53 & $1.12-2.10$ \\
\hline
\end{tabular}




\section{Anaemia prevalence and risk factors}

The haemoglobin concentration ranged from $4.3 \mathrm{~g} / \mathrm{dl}$ to $18.4 \mathrm{~g} / \mathrm{dl}$ with mean $( \pm \mathrm{SD}$ ) level of $10.9 \mathrm{~g} / \mathrm{dl}( \pm 1.8 \mathrm{~g} / \mathrm{dl})$. The overall prevalence of anaemia was $47.4 \%$ (95\% CI: $45.5 \%-49.3 \%)$. Of these, $35.3 \%, 9.9 \%$ and $2.1 \%$ had mild $(\mathrm{Hb}=9-10.9 \mathrm{~g} / \mathrm{dl})$, moderate $(\mathrm{Hb}=7-8.9 \mathrm{~g} / \mathrm{dl})$ and severe $(\mathrm{Hb}<7 \mathrm{~g} / \mathrm{dl})$ anaemia, respectively. Mean (SD) BMI was 25.3 \pm 3.5 , and anaemic women had a lower BMI $(24.9 \pm 3.4)$ than non-anaemic women $(25.5 \pm 3.6 ; P<0.001)$. The prevalence of anaemia in relation to demographic, socioeconomic and obstetric characteristics is shown in Table 1.

In the univariate analysis, the prevalence of anaemia was significantly higher among women recruited at Pasua clinic $(P<0.001)$, women with partners who had primary education $(P=0.04)$, women with a monthly income $<\mathrm{US} \$ 30 /$ month $(P<0.001)$, and women with malaria $(P=0.002)$. Age, marital status, maternal education level, employment, smoking, partners occupation, number of pregnancies, number of children, gestation age, history of stillbirth and history of intake of iron tablets during pregnancy were evaluated, and found not to be associated with anaemia (Table 1).

Table 2: Prevalence and severity of anaemia by HIV status among pregnant women in Moshi

\begin{tabular}{lllll}
\hline Type of anaemia & Hb level $(\mathrm{g} / \mathbf{d})$ & No. of pregnant $\mathbf{w}$ & HIV status $\mathbf{( \% )}$ & \\
& & & Positive $\mathbf{( N = 1 0 4 )}$ & Negative (N=1153) \\
\hline Mild & $9-10.9$ & 937 & 35.5 & 35.1 \\
Moderate & $7-8.9$ & 263 & 15.2 & $9.5^{* *}$ \\
Severe & $<7$ & 57 & 3.8 & $2.0^{*}$ \\
\hline
\end{tabular}

** OR 1.96 (95\% CI: $1.25-3.08) ; \mathrm{p}<0.003 ; \quad *$ OR 2.3 (95\% CI: $1.01-5.24) ; P=0.04$

The prevalence of HIV was $6.9 \%$. The prevalence of anaemia was significantly higher among HIV-positive women (56.5\%; N=104) than HIV-negative women (46.7\%; N=1153); OR 1.49 (95\% CI: 1.09-2.01). The HIV-positive women also had significantly higher prevalence of both moderate and severe anaemia (Table 2). In multivariate analysis anaemia was independently associated with malaria $(P<0.005)$, HIV $(P=0.008)$, clinic of enrolment $(P<0.001)$ and markers of low socio-economic status e.g. earning less than $<$ US $\$ 30 /$ month $(P=0.03)$, lack of any income $(P<0.001)$ and renting a single room $(P=0.01)$ (Table 1$)$.

Table 3: Perinatal outcomes among anaemic and non-anaemic pregnant women in Moshi

\begin{tabular}{|c|c|c|c|}
\hline Variable & $\begin{array}{l}\text { Non-anaemic } \\
(\mathrm{n}=1176)\end{array}$ & $\begin{array}{l}\text { Mild/moderate } \\
(\mathrm{n}=1029)\end{array}$ & $\begin{array}{l}\text { Severe anaemia }^{\dagger} \\
(\mathrm{n}=51)\end{array}$ \\
\hline $\begin{array}{l}\text { Premature birth } \\
<37 \text { weeks } \mathrm{n}(\%)\end{array}$ & $16(1.4)$ & $12(1.2)$ & $1(2.0)$ \\
\hline Birth weight $(\mathrm{g})$ & $3152 \pm 458$ & $3121 \pm 451$ & $2923 \pm 458$ \\
\hline $\begin{array}{l}\text { Mean } \pm \mathrm{SD}^{*} \\
<2500 \text { grams }(\%)^{*}\end{array}$ & $46(3.9)$ & $54(5.2)$ & $9(17.6)$ \\
\hline $\begin{array}{l}\text { Birth length }(\mathrm{cm}) \\
\text { Mean } \pm \mathrm{SD}^{* *}\end{array}$ & $49.2 \pm 1.9$ & $49.0 \pm 1.9$ & $48.5 \pm 1.8$ \\
\hline $\begin{array}{l}\text { APGAR score at } 5 \mathrm{~min} \\
\text { Mean } \pm \text { SD } \\
\text { Perinatal mortality }\end{array}$ & $9.8 \pm 0.1$ & $9.7 \pm 0.2$ & $9.6 \pm 0.2$ \\
\hline $\mathrm{n}(\%)$ & $21(1.8)$ & $13(1.3)$ & $1(2.0)$ \\
\hline
\end{tabular}

${ }^{\S} \mathrm{Hb} 11 \mathrm{~g} / \mathrm{dl}$ or more; ${ }^{*} \mathrm{Hb} 7-10.9 \mathrm{~g} / \mathrm{dl} ;{ }^{+} \mathrm{Hb}<7 \mathrm{~g} / \mathrm{dl} ;{ }^{*} P=0.001 ;{ }^{* *} P=0.007$ 


\section{Effect of anaemia on perinatal outcomes}

Delivery information was available for $85 \%$ (2256) of the 2654 enrolled women; $86 \%$ (1080) for anaemic women and $84 \%$ (1176) for non-anaemic women $(P>0.2)$. The mean birth weight and length were $3132.9 \pm 456.3$ grams and $49.1 \pm 1.9 \mathrm{~cm}$, respectively. Infants of women with severe anaemia weighed $\sim 230$ grams less than women without anaemia $(P=0.001)$, and were $\sim 1 \mathrm{~cm}$ shorter compared to infants of women without anaemia $(48.5 \mathrm{~cm} v s .49 .2 \mathrm{~cm})(P=0.05)$. The risk of LBW increased with severity of anaemia. Compared with non-anaemic women, the risk for LBW was 1.3 times higher (95\% CI: 0.8-1.9) in women with mild anaemia, 1.7 times higher $(95 \%$ CI: 1.1-3.1) in women with moderate anaemia and 5.3 times higher (95\% CI: 2.4-11.5) in women with severe anaemia. Anaemia was not associated with low APGAR scores, preterm delivery or perinatal mortality. In logistic regression having HIV, malaria, maternal BMI and anaemia in the model, the risk of LBW was still high in women with severe anaemia OR 4.8 (95\% CI: 2.210.6) and moderate anaemia OR 1.6 (95\% CI; 1.0-2.9), respectively (Table 3).

\section{Discussion}

The study results showed that approximately one in two pregnant women in Moshi, attending for routine antenatal care was anaemic $(47 \%)$ despite the national policy of routine iron supplementation and intermittent preventive treatment (IPT) for malaria with SP. The prevalence observed is similar to that reported for pregnant women in Ethiopia $42 \%$ (Desalegn, 1993), but lower than that in pregnant women (60-77\%) in Dar es Salaam-Tanzania (Kidanto et al., 2009; Massawe et al., 1996), Sudan (Adam et al., 2005; Haggaz et al., 2010), Nigeria (Uneke et al., 2007) and Burkina Faso (Meda et al., 1999). Although there are geographical variations of anaemia within Tanzania, the prevalence observed in this study in the northern zone is high. According to the $\mathrm{WHO}$, a severe public health problem exists if the prevalence of anaemia is $\geq 40$ in any group (de Benoist et al., 2008). There is thus a need to re-evaluate or strengthen the current strategies to control anaemia among women of reproductive age.

Women infected with malaria had a 5-fold higher risk of anaemia than women without malaria. Malaria has also been reported as a primary cause of anaemia in pregnancy by elsewhere in Africa (Verhoeff et al., 1999; Antelman et al., 2000; Crawley, 2004; Adam et al., 2005). Few women had malaria in this study, but we may have underestimated the prevalence in pregnancy because blood smear was the diagnostic tool instead of placenta histology which is the gold standard. The strong association between malaria and anaemia however, calls for strengthening of available malaria interventions in pregnancy including the use of intermittent preventive therapy (ITP) and insecticide-treated nets (ITN). Available statistics indicate that less than a third of pregnant Tanzanian pregnant women in Tanzania use ITN (THMIS, 2008).

The strategy of supplementation with iron and folic acid, ITP for malaria prevention and de-worming during pregnancy, which was in place during the study, if adhered to, has shown to be cost-effective in reducing anaemia (Crawley, 2004; THMIS, 2008). However, $42 \%$ of the women reported that they hadn't taken SP for IPT and 20\% hadn't taken iron supplement at all though they were in the $3^{\text {rd }}$ trimester and had attended antenatal care more than once. Recent surveys in Tanzania have also shown that about $39 \%$ of pregnant women do not take iron and 
folic acid supplements at all during pregnancy (TDHS, 2005; THMIS, 2008). It may be that most pregnant women with mild or moderate anaemia are asymptomatic, and because they feel well, do not appreciate the need for medication, partly explaining the poor compliance (Levin, 1986; Crawley, 2004). To effectively reduce anaemia, coverage of pregnant women receiving recommended iron supplement and de-worming needs to be $>80 \%$ and at least $60 \%$ of pregnant women should sleep under ITN (de Benoist et al., 2008). With high antenatal attendance (94\%) in Tanzania, the opportunity should be used to emphasize the importance of anaemia prevention in pregnancy. Health promotion on nutrition and advantages of using ITN should also be emphasised.

The study found an association between anaemia and markers of low socio- economic status. Like in other studies elsewhere, having no income or low income was associated with anaemia in this study (Desalegn, 1993; Meda et al., 1999; TDHS, 2005). The clinic with higher prevalence of anaemia (Pasua), is located in a poorer neighbourhood than Majengo clinic. Integrated approaches to anaemia prevention beyond the health sector are required. Replenishing iron stores and correcting anaemia in between pregnancies is especially vital in Africa where fertility rates are high and intervals between pregnancies are short and malaria is endemic.

The risk of delivering a LBW infant was higher in anaemic women, and increased with severity of anaemia. This supports previous observations showing that the odds of delivering a LBW infant when a woman is anaemic, range from 1.9-5.1 (Lone et al., 2004; Adam et al., 2007; Haggaz et al., 2010; Kidanto et al., 2009). LBW is one of the major causes of the 4 million neonatal deaths every year in developing countries. Neonatal deaths account for $38 \%$ of child deaths under age of five (Lawn et al., 2005). If the Millennium Development Goals to reduce the number of child deaths under age of 5 years, by two-thirds by 2015 is to be achieved, a substantial reduction of neonatal deaths is required. Reducing the incidence of LBW births is thus vital and addressing maternal nutrition and preventing anaemia may be one of the strategies to prevent LBW in this setting (Adam et al., 2007; de Benoist et al., 2008).

A higher prevalence of moderate and severe anaemia was observed among HIV-positive women than HIV-negative women. Similar findings have been reported elsewhere in Tanzania, Burkina Faso and Nigeria (Meda et al., 1999; Antelman et al., 2000; Uneke et al., 2007). HIV, like anaemia is prevalent among pregnant women in Africa. Anaemia is a frequent complication among HIV-positive individuals and has been associated with faster HIV disease progression and mortality (Johannessen et al., 2008). Thus anaemia care and closer follow-up is especially important in HIV-positive pregnant women.

Anaemia prevention is also challenging in prevention of mother-to-child HIV transmission (PMTCT) programmes. The use of antiretroviral prophylaxis (ARV) during pregnancy is one of the interventions that have shown a positive impact in reducing HIV transmission to infants (WHO, 2006). A pregnant woman who does not need ARV treatment for herself, and has haemoglobin $>8 \mathrm{~g} / \mathrm{dl}$, should be given zidovudine (AZT) from 28 weeks of gestation until delivery and for those with a CD4 count $<200$, triple therapy should be given. AZT and lamivudine should continue for 7 days postpartum (WHO, 2006). A major challenge is that most primary care clinics do not have the means to check for anaemia on site, while prolonged AZT use has a well known haematological toxicity. Thus 9\% of HIV-positive with 
$\mathrm{Hb}<8 \mathrm{~g} / \mathrm{dl}$ in this study would have been given AZT. Studies have also shown AZT to cause anaemia in pregnant women as early as 4 weeks after starting therapy (Areechokchai et al., 2009). Thus prolonged use even in women with moderate anaemia is of concern as AZT might worsen their haemoglobin level. The need of introducing onsite $\mathrm{Hb}$ measure at every clinic offering ANC and PMTCT care can not be overemphasized. The HemoCue machine which is relatively cheap and easy to use is recommended (Sari et al., 2001). The use of this or similar instruments will help to offer regular monitoring and prompt detection of anaemia.

The study had some limitations. The causes of anaemia were not identified. This information is important in planning interventions, adapting them to local causes. Seasonal variations were not assessed nor were dietary habits. Also the loss of follow up ( 15\%) of the women from enrolment to delivery might have biased the estimates of perinatal outcomes; we may have thus underestimated the effect if those lost experienced higher perinatal morbidity and mortality.

In conclusion, anaemia in pregnancy is a severe public health problem in northern Tanzania. Maternal anaemia was associated with malaria, HIV, low income and increased risk of LBW. Interventions for prevention and control of anaemia should be strengthened especially regarding compliance with iron supplementation, malaria and parasitic infection control. Anaemia should be monitored closely in HIV positive women. The need to prevent anaemia in all women of reproductive age is urgent, requiring a life cycle approach to improving nutrition so that women will enter pregnancy with appropriate levels of iron stores.

\section{Acknowledgements}

We are grateful to the women who participated in the study. We thank the team of nurses and laboratory staff at Majengo and Pasua clinics for their hard work and also the Tanzanian Ministry of Health and the District Medical Officers for allowing the study to be conducted. We also thank Robert K. Stallman for critical review of the manuscript. The study was funded by a grant from the Letten Foundation of Norway.

\section{References}

Adam, I., Khamis, A.H. \& Elbashir, M.I. (2005). Prevalence and risk factors for anaemia in pregnant women of eastern Sudan. Transactions of the Royal Society of Tropical Medicine and Hygiene 99, 739-743.

Adam, I., Babiker, S., Mohmmed, A., Salih, M., Prins, M. \& Zaki, Z. (2007) Low body mass index, anaemia and poor perinatal outcome in a rural hospital in eastern Sudan. Journal of Tropical Pediatrics 54, 202-204.

Allen, L.H. (2000) Anemia and iron deficiency: effects on pregnancy outcome. American Journal of Clinical Nutrition 71(Suppl), 1280S-1284S.

Antelman, G., Msamanga, G., Spiegelman, D., Urassa, E.J., Narh, R., Hunter, D. \& Fawzi, W. (2000) Nutritional factors and infectious disease contribute to anemia among pregnant women with Human Immunodeficiency Virus in Tanzania. Journal of Nutrition 130, 19501957. 
Areechokchai, D., Bowonwatanuwong, C., Phonrat, B., Pitisuttithum, P. \& Maek-a-Nantawat, W. (2009) Pregnancy outcomes among HIV-infected women undergoing antiretroviral therapy. The Open AIDS Journal 3, 8-13.

Crawley, J. (2004) Reducing the burden of anaemia in infants and young children in malariaendemic countries of Africa: from evidence to action. American Journal of Tropical Medicine and Hygiene 71 (Suppl. 2), 25-34.

de Benoist, B., McLean, E., Egli, I. \& Cogswell, M. (2008) Worldwide prevalence of anaemia 19932005: WHO Global Database on Anaemia. Geneva: World Health Organization.

Desalegn, S. (1993) Prevalence of anemia in pregnancy in Jima town, south-western Ethiopia. Ethiopian Medical Journal 31, 251-258.

Haggaz, A.D., Radi, E.A. \& Adam, I. (2010) Anaemia and low birth weight in Western Sudan. Transactions of the Royal Society of Tropical Medicine and Hygiene104, 234-236.

Johannessen, A., Naman, E., Ngowi, B.J., Sandvik, L., Matee, M.I., Aglen, H.E., Gundersen, S. \& Bruun, J.N. (2008) Predictors of mortality in HIV-infected patients starting antiretroviral therapy in a rural hospital in Tanzania. BMC Infectious Diseases 8:52.

Kidanto, H.L., Morgen, I., Lindmark, G., Massawe, S. \& Nystrom, L. (2009) Risk for preterm delivery and low birth weight are independently increased by severity of maternal anaemia. South African Medical Journal 99, 98-102.

Lawn, J.E., Cousens, S., Zupan, J. for the Lancet Neonatal Survival Steering Team (2005) 4 million neonatal deaths : when ? where ? why ?. Lancet 365, 891-900.

Levin, H.M. (1986) A benefit-cost analysis of nutritional programs for anaemia reduction. Research Observer 2: 219-245.

Lone, F.W., Qureshi, R.N. \& Emanuel, F. (2004) Maternal anaemia and its impact on perinatal outcome. Tropical Medicine E International Health 9: 486-490.

Massawe, S., Urassa, E., Lindmark, G., Moller, B. \& Nystrom, L. (1996) Anaemia in pregnancy: a major health problem with implications for maternal health care. African Journal of Health Sciences 3, 126-132.

Meda, N., Mandelbrot, L., Cartoux, M., Dao, B., Ouangre, A. \& Dabis, F (1999) Anemia during pregnancy in Burkina Faso, West Africa, 1995-96: prevalence and associated factors. Bulletin of the World Health Organization 77, 916-922.

Msolla, M.J. \& Kinabo, J.L. (1997) Prevalence of anaemia in pregnant women during the last trimester. International Journal of Food Science and Nutrition 48, 265-270.

Msuya, S.E., Mbizvo, E.M., Uriyo, J., Stray-Pedersen, B., Sam, N.E., Hussain, A. (2006) Predictors of failure to return for HIV test results among pregnant women in Moshi, Tanzania. Journal of Acquired Immune Deficiency Syndrome 43, 85-90.

TDHS (2005) Tanzania Demographic and Health Survey 2004-2005. Dar es Salaam, Tanzania: National Bureau of Statistics and ORC Macro.

Sari, M., de Pee, S., Martini, E., Herman, S., Bloem, M.W. \& Yip, R. (2001) Estimating the prevalence of anaemia: a comparison of three methods. Bulletin of the World Health Organization 79, 506-511.

Scholl, T.O. \& Hediger, M.L. (1994) Anaemia and iron-deficiency anaemia: compilation of data on pregnancy outcome. American Journal of Clinical Nutrition; 59: 492S-500S. 
THMIS (2008) Tanzania HIVIAIDS and Malaria Indicator Survey 2007-08. Dar es Salaam, Tanzania. National Bureau of Statistics and ORC Macro.

Uneke, C.J., Duhlinska, D.D. \& Igbinedion, E.B. (2007) Prevalence and public health significance of HIV infection and anemia among pregnant women attending antenatal clinics in southeastern Nigeria. Journal of Health Population and Nutrition 25, 328-35.

URT (2003) 2002 Population and Housing Census General Report. Central Census Office. National

Bureau of Statistics, President's Office, Planning and Privatization. Government Printers,

Tanzania. 203 pp.

Verhoeff, F.H., Brabin, B.J., Chimsuku, L., Kazembe, P. \& Broadhead, R.L. (1999) An analysis of the determinants of anaemia in pregnant women in rural Malawi-a basis for action. Annals of Tropical Medicine and Parasitology 93, 119-133.

WHO (2006) Antiretroviral Drugs for Treating Pregnant Women and Preventing HIV Infections in Infants: Towards Universal Access: Recommendations for a Public Health Approach. World Health Organization, Geneva. 